deal less discomfort to the patient, but severe postoperative dangers are often prevented.

This method is just as applicable to alcoholic patients as any other method of anesthesia. I have administered it to many of the patients at the St. Alexis Hospital during a period of one and a half years, and at Mount Sinai Hospital, Cleveland, where I have been staff anesthetist for a period of three years.

The total amount of anesthetic used for the average patient during an operation, lasting from one to one and one-half hours, will be from 5 to 7 ounces, and this, I may add, is less than the average amount I have found necessary when using the cone.

The disadvantages to many who have tried this method are, first, getting the patient under the influence and, second, keeping the patient under the control of the anesthetic. However, if one recalls his first experiences in giving chloroform or ether, he will remember that he experienced not only the same difficulties, but only too often was confronted by the more serious problem of bringing the patient out from a profound anesthesia. By the drop method the dangers of profound anesthesia are less than when using the cone; and for this reason, if for no other, it is a safer method in the hands of the inexperienced.

If the cone is to be preferred to the mask for the administration of ether, then use the open cone. Pour the ether, in small quantities, in from the top, lower the cone gradually, do not bring it in close contact with the face, and do not wrap a towel around the chin and cone. If the ether is given in this manner and compared with the usual method, the anesthetist will note such a marked improvement in so many points in the anesthetic as to arouse his astonishment. A lesser quantity of ether will be used, the patient will be just under and will awaken very soon after removing the cone.

The advantages of the ether-air anesthesia are well demonstrated in operations within the mouth, when the anesthetic be given through a funnel, covered with layers of gauze and containing pieces of gauze, from which two rubber tubes lead to the nostrils. Here the ether is poured gradually on the gauze and mixed with the air ad libitum.

After having given 370 chloroform anesthetics, 260 anesthetics by means of the Allis or similar cones. and over 650 anesthetics by the open or drop method, I desire to state as my positive convictions that, from all points of view and after consideration of the many factors which must be considered in administering an anesthetic, I firmly believe that the open or drop method of giving ether is far superior to the closed or cone method. This open drop method may be properly designated ether-air anesthesia.

1242 Willson Avenue.

\section{DANGERS IN THE USE OF ADRENAL PREPA-} RATIONS.

F. C. BENNETT, M.D. LORING, LA.

In an article in The Journal, Oct 13, 1906, Dr. B. H. Potts, of Philadelphia, warns the profession of some of the dangers of suprarenal preparations. The following case illustrates a danger in the indiscriminate use of the drug:

A negro, aged 26, male, very rugged and healthy, had a stricture of the urethra. After some difficulty I succeeded in pass- ing a No. 24 French sound. When the sound was withdrawn considerable blood followed it, which greatly alarmed the patient. Thinking to quiet his fears $I$ injected into the urethrs about half a dram of adrenalin chlorid (1-1000). In about thirty seconds the patient became restless and moved about, staggered and was laid on the couch. He complained of intense pain about the heart and his breathing was labored and very rapid. The heart beat was so fast that I could not count it. The conjunctiva was blanched. Profuse perspiration broke out all over the body, and the extremities became very cold. The man declared that he was dying and I was inclined to believe him. In about five minutes he began to cough and spat up mouthfuls of bloody froth. The coughing and spitting of blood continued for over an hour. The puIse, which had been very hard, became soft and slow.

The patient gradually became quieter and the symptoms subsided. He slept fairly well the following night and rose the next day very little the worse for his experience.

I gave him morphin, atrophin and nitroglycerin hypodermatically during the continuance of the alarming symptoms.

\section{ETHYL CHLORID AS A GENERAL ANES-} THETIC.

\section{A. E. OSMOND, M.D. CINCINNATI.}

I have lately noticed in The JournaL various articles on the use of ethyl chlorid as a short general anesthetic, and some specially constructed masks.

To my mind the latter are too expensive for the general practitioner, and I desire to present a method that $I$ use in the receiving ward of the Cincinnati Hospital.

With the patient on his back, I place over his mouth and nose two layers of thin gauze. Over this I place a tin or glass funnel around the bottom of which is wrapped a towel, as shown in the accompanying illustration. The ethyl chlorid is sprayed down the small end of the funnel.

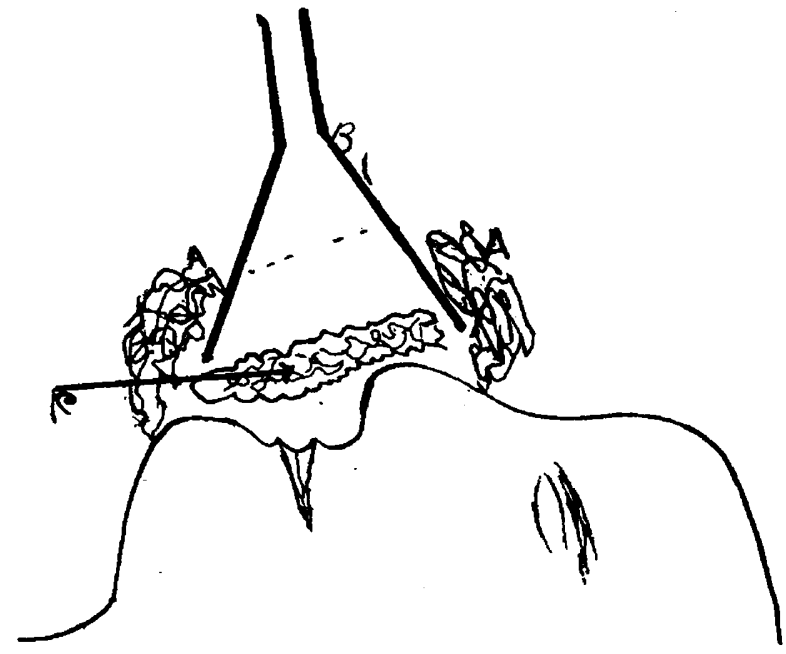

A, towel ; B, funnel ; C, gauze.

The gauze keeps the nose from being frozen, and the towel prevents too great a loss of ethyl chlorid, yet gives free access of air, so that the vapor can not be too concentrated. The patient readily goes to sleep.

The expense of such an outfit is about 10 cents; it works equally as well as the more expensive apparatus, and can be had at a moment's notice. I use it daily in any case demanding a short general anesthesia, as, for instance, to reduce a dislocated shoulder or set a fracture, and at all times with happy results. On an average about 10 c,c. of ethyl chlorid are used for each anesthetic. 